Positioning the educational researcher through reflections on an autoethnographical account: On the edge of scientific research, political action and personal engagement

Elias Hemelsoet

Department of Social Welfare Studies, Ghent University, Ghent, Belgium

Postal address: Henri Dunantlaan 2, B-9000 Ghent, Belgium

Email: elias.hemelsoet@ugent.be 


\section{Positioning the educational researcher through reflections on an autoethnographical account: On the edge of scientific research, political action and personal engagement}

Ethnographic fieldwork is subject to a number of tensions regarding the position of the researcher. Traditionally, these are discussed from a methodological perspective, and draw attention to issues such as 'objectivity' of the research and the supposed need for 'distance' in the process of knowledge-building. Approaching the issue from a different angle, this article provides a reflection on the positionality of the researcher through an autoethnographical account based on fieldwork with socially excluded groups. Rather than reflecting on (dis)advantages of proximity for the research process, it explores from a personal stance how this role interacts with other roles in the researcher's life (e.g. being a volunteer, a citizen, an advocate, a moral being, etc.). Raised awareness about this intrinsic positionality of the researcher calls for a situated conceptualisation of professionalism and science. The author furthermore explores how an autoethnographical approach relates to educational research, and substantiates the educational meaning of autoethnography for science in general.

Keywords: autoethnography; personal engagement; positionality; political action; qualitative research

\section{Introduction}

[...] I cannot drop the feeling that this matters. It seems so important, what we are doing here for these people: to give them what they need most, to provide them what is most indispensable for their bare survival. This is what makes a difference in people's lives, and isn't that what it is all about: to make a difference? But still, I feel uncomfortable and I am wondering what I am doing here. This is supposed to be my work. Am I not the researcher, who is not merely the volunteer he was before? And are the things we are doing here not against the grain of everything I have learned as an educator and social worker: that this kind of 'help' is not helpful at all...? It only further affirms people's dependence of what is supplied to them free of obligations and thus restricts their emancipation rather than supporting it. That is not just theory, it is as well what I have painfully come to recognise 
by my own experience throughout the past few years: that in the end, for many of them, not much of their situation changes. Maybe I am just too involved, and I lose some of the distance that is required for the researcher to get a clear and nuanced overview of things. Was that not also what it was all about? (Field notes of voluntary work in the weekly food distribution for irregular migrants in a local charity organisation)

Doing ethnographic research and participatory fieldwork is unavoidably bound up with questions on the position of the researcher (e.g. Gobo 2008; Hastrup 2001; Okely 2001; Salzman 2002). Discussions related to this situatedness may vary in form and occupy a broad range of discursive manifestations, but are omnipresent in the history of both ethnography and qualitative inquiry at large. Recently, postmodernist approaches by, for example, feminist (e.g. Lather 2007), anti-racist (e.g. Dei and Gurpreet 2005), postcolonial (e.g. McLeod 2000) and indigenous scholars (e.g. Tuhiwai Smith 1999) have gained influence. These express an increasing awareness of the untenability of the myth of the positivistic, invisible researcher-narrator (Hastrup 1995), as 'the notion of a neutral, objective researcher was destabilised and deconstructed decades ago,' and it must be recognised that 'knowledge and understanding are historically and contextually grounded' (De Graeve 2012, 16). In other terms, and with distinct focuses, related discussions on the position of the researcher are carried on with regard to the relation between researchers, practitioners and/or research subjects (e.g. Boog et al. 1998; Brinkmann 2007; Gitlin 1990; Wagner 1997). Opinions vary on how these relationships should be conceived of within particular research settings and who will benefit from which kind of research. Depending on the answer to this question, close, almost intimate cooperation or more limited forms of engagement will be preferred. This includes discussions on the desirability of various forms and degrees of participation based on efficiency arguments (participation as a tool for achieving better outcomes), 
and equity and empowerment arguments (participation as a process that enhances the capacity of individuals to improve or change their own lives) respectively (Cleaver 2001). Other studies reflect upon power dynamics, which are an unavoidable and essential part of social research (e.g. Nader 1995; Priyadharshini 2003; Sassen 2000). Questions with regard to both the extent to which and how participants should be involved remain in abeyance, and continue to cause a lot of disagreement among scholars. There is growing consensus though that 'science is no longer seen as disinterested and value-free,' and that it 'reveals itself as a performative intervention' (Smeyers 2006, 483). The insight that 'research projects are interventions in the lives of researchers and practitioners' (Wagner 1997, 14) deserves attention in the research process. Within various action research traditions, this is further radicalised (e.g. Day et al. 2002; Reason and Bradbury, 2008). Action research not only recognises the idea of interventionism, but moreover intends it. Action and reflection are brought together 'in the pursuit of practical solutions to issues of pressing concern to people, and more generally the flourishing of individual persons and their communities' (Reason and Bradbury 2008, 4).

This article provides a reflection on the positionality of the researcher throughout an autoethnographical account based on a fieldwork study with socially excluded groups. It thus subscribes to a tradition that decidedly and deliberately places autobiographical reflections at the heart of the research process (Ellis 2004, 2007; Ellis, Adams, and Bochner 2011; Ellis, Holman Jones, and Adams 2013; Holt 2003; Reed-Danahay 1997; Spry 2001). 'Central to this process is coming to terms with our own ambivalence regarding our status as academics' (Gaztambide-Fernández and Howard 2012, 289) in the field. That implies that reflections not only concern our work but also our personal 
life, in such a way that who we are as a person is also scrutinised and critiqued (Ellis 2004). In that sense, it implies a particular openness and it involves the exploration of moments of 'vulnerability' in which we expose ourselves to the intimate process of establishing and negotiating relationships in the field (Behar 1997; GaztambideFernández and Howard 2012).

Two occasions in particular appealed when deciding on an autoethnographical approach. First, there was the personal trajectory of my $\mathrm{PhD}$ research project, in which charity, advocacy and scientific work were closely knit, but were nonetheless often in tension with each other. That experience strengthened the belief that dealing with the often complicated confrontation between personal engagements and theoretical insights would have to form an indispensable part of the research project itself in order to give it a place both in scientific knowledge-building and in my personal life. Second, leading scholars in the field reveal the relevance of such personal narratives for research. Throughout their apparently trivial stories, it is shown that there is something very unsatisfying about just making a rational case, as this 'takes away the experience' (Ellis et al. 2008, 257). The suggestion that the question 'What will qualitative inquiry become?' is in fact a political question - which is moreover in the hands of young researchers (see Ellis et al. 2008, 279) - closely links to my own research experiences. The challenge of giving an answer to that question, and to the evocation directed to young interpretive/participatory/activist qualitative researchers, is the gauntlet I want to take up in this contribution.

Obviously, my ambition is not only to find answers to the personal struggle I am dealing with when trying to position myself in a 'field' that in the end appears to be my 
own life world. As Denzin (1997, xvii) writes, 'these texts are not just subjective accounts of experience, they attempt to reflexively map multiple discourses that occur in a given space'. By means of an autoethnographical account, I also hope to contribute to the scientific discussion on the position of the researcher. In particular, I will focus on the way an autoethnographical approach is closely linked with my own background as an educational scientist, since I neither put the research subject nor the researcher at the heart of inquiry, but rather their mutual interrelation. In so far as autoethnography is only involved with the self, it runs the danger of being overly narcissistic and selfindulgent (Coffey 1999). But as Spry $(2001,708)$ puts it, this approach is not situated in a social vacuum: 'autoethnographical texts express more fully the interactional textures occurring between self, other and contexts in ethnographic research'. I will thus further explore how an autoethnographical approach relates to educational research. Finally, I will argue that autoethnography also has an educational meaning for science in general. Its mirroring function provides opportunities for a down-to-earth move within social sciences. It forces academia to reflect continuously about its proper social embeddedness in relation to ethical concerns (e.g. Etherington 2007), matters of social justice (e.g. Beck and Maida 2013; Elliott 2006; Marullo and Edwards 2000) and human emotions (e.g. Behar 1997). I will now turn to some reflections on my own autoethnographical study as a first step to accomplish that challenge.

\section{The study and occurring tensions}

My PhD study was conducted in the period 2007-13 and gives an interpretive account of the meaning of the right to education for Roma children in Ghent, Belgium. This explorative inquiry of present practices consists of intensive fieldwork and aims to 
contribute to the realisation of this right within a demarcated geographical area. Its explorative character is explained by the fact that there is hardly (if any) previous scientific research available on the topic in Flanders, mainly due to the recent arrival of most Roma residing there. Consequently, the scope of the research was rather broad in order to gain an integrated overview of practices with regard to the topic of interest. The fieldwork includes a large number of qualitative interviews with relevant stakeholders in the education, integration and welfare sector; participatory observation in schools and various other organisations; attendance of relevant meetings and consultations; participation in steering committees and boards; and finally, volunteering in various initiatives. The latter is not merely the consequence of doing research. Quite the reverse: four years of voluntary work in a local charity organisation that preceded my research project (in combination with my background as an MA in educational sciences) led me to choose this research topic once I started working at the university. This voluntary organisation provides support to refugees, asylum seekers and irregular migrants by means of social service consultations, weekly food distributions, home visits, and second-hand shops with furniture, clothes, antiques and books. It forms part of an umbrella organisation, which proved to be of great help to build up a network of relevant stakeholders in the fields involved with this 'target group.' As such, 'obtaining an overview of relevant initiatives in the field' occurred rather spontaneously, and 'gaining access' to these did not require any added strategies to the voluntary work I had been doing before I began my study. But my pre-existing position in the field was not only accompanied by access advantages; it also incurred some complex tensions that had to be dealt with, both at a personal and an interpersonal level. 
First and foremost, much of the charitable work does not match, not to say conflicts, with the educational ideals I was initiated into during my university studies. From an educational and social work perspective, charitable work does not contribute to the emancipation of the people involved in a structural way (Marullo and Edwards 2000), as it is based on voluntariness and it is consequently not enforceable (see Buchanan 1987). Rather than making people autonomous, it is said to run the risk of reaffirming their dependent position and it 'typically ends up reproducing the status quo' (Marullo and Edwards 2000, 896). On the principle that 'it is better to teach people how to fish than to give them fish,' self-leadership, autonomy, empowerment, emancipation and other similar concepts are put to the fore as educational ideals worth pursuing. As such, charity is often contrasted with social justice (for a comparative analysis of these concepts, see Buchanan 1987). But as expressed in the introductory quote of this article taken from my fieldwork notes, though such a view may be theoretically sound, it is not evidently so in lived, day-to-day experience. Does the desirability of an emancipatory approach seeking structural ameliorations exonerate us from the duty to help those in need in an educationally imperfect, i.e. possibly paternalistic, dependency-affirming way by providing them food, clothes or shelter? Without further turning this issue into an or-or question to be decided upon, it is obvious that the encounter with homeless irregular migrants in a particular situation poses not only methodological and deontological questions, but may moreover confront the researcher with ethical issues that touch upon him or her as a person. There are problems with both involvement and detachment in such situations (see Elias 1956), which require attention and reflection for researchers. Moreover, professional requirements may be at odds with personal beliefs and emotions. These tensions may imply paradoxical situations in which clear answers are not ready to hand. In the case of my own research, I decided to continue 
both my work as a researcher and as a volunteer, although obviously the mutual influence of both roles is undeniable and not neutral.

A second set of tensions relates to the situatedness of the researcher in various social contexts. While in the foregoing the researcher's personal conflicts were referred to, I now turn to consequences at the interpersonal level. The tensions at stake are not only personal challenges for the researcher, they also bring about different positions in the field. Being a (charity) volunteer, a researcher or a human rights activist - to give but three examples relevant to this case - may seem very different things, but may not be as clearly distinguishable into categories when lived by the same person. At many points, it may be unclear to other stakeholders, such as involved Roma people, professionals or volunteers, as well as policymakers and academics, which particular role has been taken by the researcher/volunteer/activist at a given moment. This was, for example, the case during the preparation of a policy document on the education of Roma in the city of Ghent. Representatives of various relevant stakeholders in the field (schools, city services, welfare organisations, Roma organisations, etc.) were invited by the city's integration service to participate in the work group that would prepare the document. Initially, I participated in the work group as a member of a Roma organisation I cofounded. Still, I considered my input in this work group to be based on my experience as a researcher rather than of an advocate of the Roma. Moreover, meetings of the work group took place during working time, which made it deontologically 'unsound' towards my employer to participate on behalf of another organisation, although I was never reprimanded for doing so. But the decisive argument to request my participation as a researcher in the work group, was that it gave me a different authority to speak on topics exceeding the scope of the activities of the Roma organisation. From that 
moment on, somebody else was seated in the work group to represent this organisation, which enabled me to introduce experiences taken from my scientific work. This clarified my role, as previously many participants repeatedly asked me to take their position during discussions due to the fact I had gotten familiar with their opinions throughout the fieldwork I had been doing with most of them previously.

Another example relates to an interview I did with a Roma family. I had known these people for a few years at that moment as they regularly came to the food distribution where I volunteered. One day I asked them whether they would consent to an interview. They did not really seem to understand what I wanted, but continued to stress that I was very welcome at their home. Such home visits of people living in squats or bad living conditions are not uncommon amongst volunteers of the charity organisation, but once I got there they were not only surprised to see my audio recording material, also throughout the interview, I was repeatedly asked why I was interested in the things I was asking - which did not really seem to fit our previously held relationship. Although I had extensively explained that I was doing research, and that this was part of my job in university, the idea of (scientific) research itself, in some way or another, seemed unfamiliar to them. That problematised the idea of informed consent (they did not know what they consented to, but agreed to do so based on a relationship of trust) but also blurred our relationship. To some, these interferences may foremost be an expression of unprofessionalism. To others adhering to postmodernist research approaches, it may be an example of a personal quest for knowledge. Some action researchers may finally state that a less strict division of different positions and partisanship can be supportive for research seeking social change (Bogdan and Biklen 1998; Greenwood and Levin 2003; Reason and Bradbury 2008). Obviously, a myriad of both methodological 
questions and tensions could be added to the former mentioned and further complicate the discussion. In what follows, it is impossible to discuss each of these tensions (on which many are very well-documented already in existing literature) extensively. I will argue that this situatedness and complexities related to the position of the researcher necessarily requires explicit attention in interpretive research. In order to answer the question of how to deal with the tensions at stake as a researcher, I will first attempt to identify the particular positionalities of the researcher that are at work in this case.

\section{Clarifying the problem: Identifying different positionalities of the researcher}

A large set of interrelated tensions constitute a highly complex situation with a continuously altering position of the researcher: it involves tensions between volunteering and professionalism; personal engagement and professional distance; insider and outsider perspectives; the private and the public sphere; abstract ideals and practical demands; objectivity and a need for change; and several others. These are not dichotomies, nor are the factual and desirable positions of the researcher on any of them definitive; they all depend upon each other and the context may change over time too. Their mutual interactions constitute the 'positionality of the researcher.' The researcher is not only a researcher though. He or she is a person with various roles, of which 'being a researcher' is but one. Like the tensions, these roles cannot be strictly separated and continuously influence each other. Too often, discussions on the insider/outsider tension and degrees of involvement, for example, are carried on as if they merely involve a methodological choice to be decided upon. Academia is thereby presented as a 'professional' sphere independent of other life domains. In these debates, the role of the researcher is evidently separated from other roles. Discussions focus on the most 
desirable way to 'shape professionalism,' and opinions vary as to which degree the researcher should be involved in or detached from their research subjects and context. But neither the 'private identity' of researchers, nor their 'public identity' as a citizen should be disregarded here. These roles too are attended by different forms of accountability that may conflict with outcomes of the professionalism debate. On the one hand, a researcher has a position in academia, and evidently has to account to scientific exigencies including methodological requirements and deontological codes (see procedural ethics; Ellis 2007); other roles may not be pleaded as an excuse for scientific deficiencies. On the other hand, a (private) moral person has to account for his/her own acts, choices and way of 'being in the world.' Depending on personal beliefs, this may be seen in an accountability towards one's self, ethical ideals, God, etc. Yet, a citizen is positioned in the public sphere and society as a whole. Evidently, this implies compliance with the law and social rules and values. Moreover, this comes with a political positionality in the broad sense of the word: one takes up his/her actorship as a citizen in a particular way that is never neutral. All of these roles merge together in the person of the researcher, and should in some way be geared to one another. As a pedagogue/researcher/stakeholder/advocate/volunteer/citizen/human being, it is my task to make sense out of these distinct but strongly entangled roles, and to do so in all life domains.

Let me now turn back to the reflections on my own study. As mentioned before, I consider my work as a volunteer in a charity organisation to a certain extent to be in tension with my scientific work as an educational researcher. These distinct roles serve various ideals which may interfere, or at worst even discord, with one another. An 
experience of uneasiness is exemplified in one of the very early reflections of my field notes:

And still I feel uncomfortable, almost perverted. Today, my involvement with these people - which motivated me to come and work here as a volunteer three years ago and subsequently to make the professional choice to do research on this topic - got in a strained relation with a different way to relate to them for the very first time. To my personal experience, 'the volunteer' and 'the researcher' seemed to be diametrically opposed to each other: the one who is disinterestedly committed to those in need and the one who 'exploits' respondents to gather research data. Building a relationship of trust may be a methodological condition for the researcher to get hold of authentic data, but at the same time (and as well for methodological reasons) this relationship needs to be limited to the one of a 'relative outsider.' However honourable the ideals of reliability and validity may be, an almost instrumentalised form of engagement as a means to bring about an image in the respondents' perception and as such to recover relevant data clashes with the way I relate and want to relate to these people. It increasingly raises the question: Is the relevance and meaningfulness of my research for these people something I truly believe in, or is it an argument I like myself to believe in order to legitimise what I am doing? (Field notes of voluntary work in the weekly food distribution for irregular migrants in a local charity organisation)

This interference of various roles not only counts for the charity work; during the research process, I also got involved in other settings in the field where I was not (or could not be) a neutral observer on the side-line: I was invited to give input to action groups, steering groups of new projects and initiatives; my opinion on the highly politicised topic of Roma integration was asked for in media interviews; and I cofounded a non-profit Roma organisation and interest group in Ghent. Although I could search for excuses for these activities that may threaten my scientific objectivity and 
neutrality by saying that I nicely separated 'working time' and 'private time,' that does not really solve the problem, as different roles do not allow themselves to be separated by a proportionate distribution of timetable partitions. It is generally recognised that the position of a researcher in the humanities can never be a neutral one, and that some form of normativity is always involved (e.g. Lincoln 1995; Wagner 1997). Evidently, this normativity is shaped by the other roles described above. Still, little attention is drawn to the reverse influence of being a researcher on these other roles. Similarly to the mutual influence each of the roles has on the others, being a researcher also adds something to these. Researchers dispose of a specific form of citizenship. As other citizens, they are political actors, yet informed in a particular way due to the knowledge gathered throughout their professional activities. For that reason, they may be favoured and privileged to take up certain other roles. To be privileged here does not mean their opinion is more valuable in a moral sense, but it does imply that the scientist's contribution is informed differently (with regard to particular topics). One might thus argue that it gives a surplus reason to researchers to take up other roles exactly because of being a researcher - they have something else to say about it. For example, when participating in the public debate on the migrations and social integration of Roma in Belgium, I dispose of background information that exceeds the limited and often very coloured information provided in the media; I became familiar with the history and living conditions of Roma in countries of origin through literature, and in my own research I obtained an overview of various perspectives of many stakeholders on the present situation. That particular background too colours what I have to say about it; but qua researcher, it does so in a particular way, which may, as I want to argue, have an added value to the public debate. The insight that being a researcher implies that one has something else to say about particular topics prompts new questions with regard to 
the goal-setting and finality of science, and educational science in particular. It could therefore be suggested, for example, that it is not only tolerable but moreover desirable for social scientists to 'take up their responsibility' by turning their scientific knowledge into a vivid leverage of discussion, action and change in the public arena. The latter does not imply that researchers are expected to run for political positions. But they may, for example, have their voice heard in public by publishing work that is less technical or written in the local language; by participating in discussion panels or in the public debate throughout the media; or by setting up or participating in steering groups of local social projects. Academic engagement in such activities could contribute to the embeddedness of social science in the public sphere and the local context. Some authors take this argument a step further and explicitly argue for a more engaged way of practicing and 'using' science as a vehicle for social change (e.g. Beck and Maida 2013). This requires both an altered conceptualisation of the researcher's identity and of science, which will be the subject of the next section.

\section{Situated professionalism and implications for the conceptualisation of science}

In the former section, attention was drawn to various tensions and roles that constitute the positionality of the researcher. This position is not univocal nor unambiguous. By definition, it is situated in a historically and geographically contingent context. An analysis of autoethnographical accounts is helpful to shift the attention not so much from research subjects to the researcher, but rather towards its positionality in the research setting, i.e. its embeddedness in the context. Raised awareness about the intrinsic positionality and relationality of the researcher calls for an adapted conceptualisation of professionalism - in particular, a situated one. This situated 
professionalism can be related to the various roles mentioned before. Most evidently, every professional is situated in a particular working environment: for the scientist, this is academia. Besides that, the researcher is also situated in society, in a policy context and in a private life (with family, friends, etc.). All of these contexts have different modi operandi, with corresponding exigencies and expectations. From an academic perspective, the researcher has to meet quality criteria and respect deontological codes; his assignment in the field is, in the first instance, to gather data that may add to the project of knowledge-building. But when entering the field, they may be confronted with other expectations: teachers, social workers or policymakers may appeal to the expertise of the researcher that may be of help to support them in their work. Moreover, the researcher qua citizen de facto has a voice in the public debate, e.g. through the right (or obligation, depending on the legal conditions) to vote in elections. This voice is not neutral, and is informed by their work as a researcher. Past experiences and personal relationships like friendships or family ties may in turn influence the interpretation of these positions. Not only in a practical sense may having a proper family restrict the time management of research: opinions of beloved ones or positive or bad experiences with, for example, a neighbouring Roma family cannot be strictly separated from the roles as researcher or citizen. In some cases, this may bring along confinements for the scientific work: loyalty to the people one is working with can, for example, restrain one's freedom to speech in certain situations, as saying certain things could undermine (personal) relations. For example, the self-referentiality of many Romani leaders, who deem their proper voice as something that should naturally be accepted and is not to be questioned, may be considered problematic as it risks the closure of dialogue, the oversimplification of things or even the exclusion of other voices (alienation of a so-called Romani elite from the grassroots is a well-documented phenomenon in the literature; 
see Vermeersch 2006). When one is confronted with such situations, bringing these up on a public forum may evidently alter the relationship with the people involved as it is critical towards their sayings, and their personal attitudes may be explicitly questioned. In that sense, situating oneself involves difficult balances, which entail opportunities as well as confinements. The researcher is not only a performer or an executor of these roles with adhering modi operandi, but has to position and to situate herself over and over again. That difficult task incurs a political actorship, including mediation in and between each of the earlier mentioned domains. Raising awareness about this situatedness and mutual influences opens opportunities for more directed and intended forms of change. These influences must not only be looked upon as unavoidable interferences for scientific accuracy and objectivity, but may turn out to fruitfully affect knowledge-building. In other words, it opens a space for an engaged exercise of scholarly activities (Beck and Maida 2013; Rappaport 1995; Skocpol 2003). Conversely, reverse influences may be beneficial too; for example, and as mentioned before, scientific work offers opportunities for a better informed citizenship. These insights prompt new questions with regard to the finalities and the conceptualisation of social science as a whole, to which I will now turn.

The obvious assignment of the researcher is to contribute to science; but what then is the assignment of social sciences? And how can we conceive of this question in relation to the situated professionalism of the researcher? Researchers have provided various answers to these questions. Accordingly, distinct paradigms in social scientific research refer to different ways to conceive of the positionality and situatedness of scientific professionalism. In actual research, these approaches only rarely appear in a pure form. Generally, it concerns hybrid forms or combinations of various approaches within a 
broader research framework. As a supplement to and in dialogue with each other, they may contribute to the production of 'valid knowledge,' which is not the outcome of any of these normative approaches in itself, but of the ongoing discussion amongst them. Although the list may not be exhaustive, the following overview offers insight in predominant paradigms providing distinct views on the role and position of the researcher with relevance to the discussion at hand. In technical-instrumental approaches, for example, value neutrality and performativity are central quality standards to the view that transfers the predominant way of working in natural sciences to the study of human reality in social sciences and humanities. Science is supposed to be productive within the pre-existing order, and serves as an instrument to find solutions to occurring social problems. In educational sciences, Brezinka (1972) is one of the most influential exponents of this view. He explicitly expels value judgments out of the scientific domain; these are subjective, thus unscientific decisions and science should not get mixed up in such affairs. His scientific positivism argues for a teleological causal-analytical-oriented approach that limits itself to the examination of necessary conditions to reach particular goals (Smeyers and Levering 2001). Utopian idealist approaches, on the other hand, disagree with the former as they expect science to contribute to a better world. How 'better' is defined remains, to a certain extent, open to discussion, but it generally concerns an increased humanisation or civilisation of the present state of affairs in order to realise some kind of ideal society. In educational terms, an explicitly normative pedagogy is implied here, of which the most well-known examples are the eighteenth and nineteenth-century great pedagogical theories of Kant, Rousseau, Pestalozzi, Froebel and Herbart. Rousseau's illustration of how an ideal citizen may be educated is in his Emile, or on education (Rousseau 1972 [1762]), and is very exemplifying. But more recent theories like the one of Freire (1970) also build on a 
utopian, more humane society. Critical deconstructionist approaches disagree with the technical-instrumental paradigm in a different way. Rather than presenting an alternative social ideal, the constitution of the present state of affairs is critically analysed. The definition of deconstruction applied here exceeds the tradition initiated by Derrida (1967), and more broadly refers to various poststructuralist attempts of dismantling structures, uncovering power relationships and identifying implicit presuppositions (see Koro-Ljungberg 2004). Achieving a critical distance from the subject of research is a requirement to fulfil that task, and is pushed forward as an educational ideal (Masschelein 2004). Interpretative explorative approaches seek for a better understanding of social reality starting from a raised awareness about the situatedness of the researcher. Meaning is socially constructed, and cannot be unfolded as a static reality open to objectification. Attention to the role of the researcher in relation to the research context is of central importance to that meaning-making process. They are not investigating a reality as an outsider, but unavoidably co-construct the social reality under investigation. As Smeyers $(2006,482)$ clarifies, 'science here is no longer seen as disinterested and value-free: instead there do not seem strict boundaries between science and society'. More specifically, 'educational research participates through dialogue in improving our practical knowledge of on-going social life but at the same time necessarily invokes a normative stance' (Smeyers 2006, 483).

Both autoethnography and situated professionalism point into the direction of approaches of research that emphasize the importance of interpretative processes in the construction of knowledge. These offer an adequate framework to shift the focus of attention to the positionality of the researcher, its relatedness with the broader context and its role-taking in the construction of meaning. The implication of these approaches 
is that social scientific research too is considered to be a socially constructed practice, the meaning of which is unremittingly under negotiation. Still, excrescences 'using' science as an instrument for external goals, such as blind forms of activism, are at most reverse perversions of any of the aforementioned views. But more moderately, approaches focusing on interpretative processes open the door to more engaged forms of scholarship. In the concluding section, the implications of such an approach for educational research are further explored.

\section{Exploring the relation between autoethnography and educational research}

The concept of educational research may be interpreted in various ways. Firstly, it refers to a discipline. In that sense, educational research is research within the domain of educational sciences, of which education in one of its various meanings (as an institution or as a practice) is the research subject. In other words, it concerns research 'on' or 'about' education. Secondly, it may refer to research for the use of educational practice. In that case, research is employed to answer questions emerging in these practices. This we could call research 'for education.' But research may also be educational 'in itself.' It is then conceived of as an educative practice questioning or reconstructing social reality. As Gitlin $(1990,444)$ writes, 'most educational research still is a process that for the most part silences those studied, ignores their personal knowledge and strengthens the assumption that researchers are the producers of knowledge'. To alter this relationship, he proposes the use of educative research - a dialogical approach that attempts to develop voice as a form of political protest. Similarly, Elliott $(2006,169)$ refers to 'educational research' as distinct from 'research on education,' defining the former in terms of 'its practical intention to realise 
educational values in action,' adding that 'in doing so, it cannot avoid taking an evaluative stance on the aims of education'. He states that 'for research to count as "educational research" it would need to be free from objectivist assumptions and the standpoint of the impartial spectator' as 'instrumental reasoning alone does not justify educational practice' (Elliott 2006, 184). In order to concretise the latter, I now turn back to my own study and the question of how it relates to the foregoing interpretations of educational research.

In some ways, each of the above definitions covers the cargo of my proper research project. With its focus on the right to education and educational practices, it certainly is a study about education. Also, it aims to serve educational practice. As a researcher, I set myself the objective to answer the questions directed to me by teachers and social workers in some way or another. The outcomes of my research should be of some use, and hopefully ameliorate the educational situation of Roma children. What this 'amelioration' may mean remains open at the beginning, and is dialogically shaped with the people that are involved throughout the research process. Although its interpretation is not predefined, it clearly also is research for education. Last but not least, my research project aims to be educative in itself. It wants to question things by redefining and adjusting them. 'Things' covers just about every aspect of the study: the role and position of the researcher, as well of research subjects; the way the context is designed; relevant policy; opinions and beliefs of various stakeholders; mutual prejudgments; theoretical assumptions; methodological choices; deontological issues, etc. My study is not an example of voice-giving to Roma, nor does it attempt to be the objective representation of a social reality. Rather, it reflects a dialogical process between various stakeholders. 
In order to understand this properly, 'dialogue' requires some specification here. It is to be distinguished from talk or conversation, as it implies 'that all participants see the discourse as important and have a say in determining its course' and it 'enables participants to work together to understand the subject being discussed' (Gitlin 1990, 447). As the researcher holding the pen, I am the 'director' of the written reflection that aims 'to identify and examine the normative truths that are embedded in a particular historical context' (Gitlin 1990, 448). That is inescapably so: I am the principle author of the study I initiated and wrote down. Still, I am not the only author of the reflected process, nor is this normative truth only mine, as the dialogue is not merely a dialogue with myself but involves other stakeholders This reflection is not merely a representation or a description of a communicative process, but forms part of that ongoing dialogue. It actively shapes this dialogue as well as mutual relations, and has an explicitly political meaning in that it 'e-ducates' in the original meaning of the word: it 'leads out' the self-evidence of a pre-existing order, thus creating moments of vulnerability and spaces for something new. It is e-educative for me throughout explicit self-reflection (for which autoethnography is of the utmost value); it is e-ducative for Roma by forcing them to reflect upon themselves, for example, when an interview is taken from them; it educates policymakers by showing them a different reality behind the letters of the law; and it is e-ducative for professionals in schools and other institutions when they are challenged by the perspectives of other stakeholders (such as the parents or policymakers) that exceed the scope of their own work.

Autoethnography is closely linked to educational research. As an approach, it commands the researcher to reflect upon their situatedness and, as was clarified before, 
it centralises the focus on their relatedness with the research context. In educational research, the focus on 'education' implies attention for the pedagogical relationship that is at the very heart of every educational process. But with regard to the educative interpretation, the connection between autoethnography and educational research may even be taken a step further. Not only do their focuses of interest on situatedness in a context and relatedness as a subject matter provide a commonality - as is the case for all interpretations of educational research - both approaches also offer opportunities to shape this situatedness and relatedness, and moreover intend to do so. Because of this intentionality, the autoethnographical approach is intrinsically educative. This conclusion has consequences that transgress the scope of educational sciences as a discipline. More particularly, it may be educative for social science as a whole by inciting reflective processes on the positionality of science itself. As Elliott $(2006,185)$ formulates it, 'the project of re-describing educational research is necessary for political reasons, since it can provide an alternative account $[\ldots]$ to realise our hope of a better, more democratic and just society'. Whatever the outcomes, these processes would affect a down-to-earth move, forcing science to reflect on how it is socially embedded, i.e. how its relation to, and situatedness in, the social reality should be conceived of. Such an 'e-ducation of science' is not merely a thought experiment, but it may prove to be helpful in order for interpretive science to make sense. It should relate to the context it is part of, be conscious of how that relation is shaped, and position itself in the construction of that relation in an unremitting dialogue.

\section{Afterword}


To conclude, let me add some comments on the position of the educational researcher. Although in the beginning of this article I may have suggested seeking clear answers to the question of how to conceive of the position of the researcher in various life domains and fields, I am forced to admit that this meta-reflection on an autoethnographical account has so far only succeeded in throwing light on that question to a limited extent. So let me dedicate some final words to that challenge. The observation that I have not so much decided upon which is the most desirable positionality of myself as a researcher, might in itself reveal an answer. The unremitting self-reflection on how to position oneself is the leverage needed for the educative exercise of keeping to question oneself and the environment in relation to one another. That choice - to continue my voluntary work in a charity organisation and combine it with advocacy initiatives for Roma while doing scientific research - is a conscious one. And I continue to consider it being a fertile one both for my scientific work and my personal development, as it unremittingly pushes me to pursue my quest. Maybe a state of abeyance can thus be recognised as fertile soil not only of educational practice and research, but also of the educative challenge of life itself. The pragmatics of life leaves the opportunity to do so open to us, and for myself I may say that has been, and continues to be, an educative experience.

\section{References}

Beck, S., and C. A. Maida, eds. 2013. Toward Engaged Anthropology. New York and Oxford: Berghahn.

Behar, R. 1997. The Vulnerable Observer: Anthropology that breaks your heart. Boston, MA: Beacon. 
Bogdan, R. C., and S. K. Biklen 1998. Qualitative Research in Education: An introduction to theory and methods (3rd ed.). Needham Heights, MA: Allyn and Bacon.

Boog, B., H. Coenen, L. Keune, and R. Lammerts, eds. 1998. The Complexity of Relationships in Action Research. Tilburg, Netherlands: Tilburg University Press.

Brezinka, W. 1972. Von der Pädagogik zur Erziehungswissenschaft. Weinheim, Germany: Beltz.

Brinkmann, S. 2007. "The good qualitative researcher." Qualitative Research in Psychology 4 (1-2): 127-144.

Buchanan, A. 1987. "Justice and charity." Ethics 97 (3): 558-575.

Cleaver, F.. 2001. "Institutions, agency and the limitations of participatory approaches to development." In Participation: The New Tyranny?, edited by B. Cooke, and U. Kothari: 36-55. London and New York: Zed Books.

Coffey, A. 1999. The ethnographic self. London: Sage.

Day, C., J. Elliot, B. Somekh, and R. Winter, eds. 2002. Theory and Practice in Action Research: Some international perspectives. Oxford: Symposium Books.

De Graeve, K. 2012. Making Families: Parenting and belonging in transnational adoption in Flanders. (PhD dissertation). Ghent, Belgium: Ghent University.

Dei, G. S., and S. J. Gurpreet. 2005. Critical Issues in Anti-racist Research Methodologies. New York: Peter Lang.

Denzin, N. 1997. Interpretive Ethnography: Ethnographic practices for the 21st century. London: Sage.

Derrida, J. 1967. Of Grammatology. Baltimore, MD and London: Johns Hopkins University Press. 
Elias, N. 1956. "Problems of involvement and detachment." The British Journal of Sociology 7 (3): 226-252.

Elliott, J. 2006. "Educational research as a form of democratic rationality." Journal of Philosophy of Education 40 (2): 169-185.

Ellis, C. 2004. The Ethnographic I: A methodological novel about autoethnography. Walnut Creek, CA: AltaMira Press.

Ellis, C. 2007. "Telling secrets, revealing lives: Relational ethics in research with intimate others." Qualitative Inquiry 13 (1): 3-29.

Ellis, C., T. Adams, and A. Bochner. 2011. “Autoethnography: An overview.” Forum: Qualitative Social Research 12 (1): art. 10.

Ellis, C., A. Bochner, N. Denzin, Y. Lincoln, J. Morse, R. Pelias, and L. Richardson. 2008. "Talking and thinking about qualitative research.” Qualitative Inquiry, 14 (2): $254-284$.

Ellis, C., S. Holman Jones, and T. Adams. 2013. Handbook of Autoethnography. Walnut Creek, CA: Left Coast.

Etherington, K. 2007. "Ethical research in reflexive relationships." Qualitative Inquiry, 13 (5): 599-616.

Freire, P. 1970. Pedagogy of the Oppressed. New York: Seabury Press.

Gadamer, H.-G. 1975. Truth and Method. New York: Seabury Press.

Gaztambide-Fernández, R. A., and Howard, A. 2012. "Access, status, and representation: Some reflections from two ethnographic studies of elite schools." Anthropology and Education Quarterly 43 (3): 289-305.

Gitlin, A. 1990. "Educative research, voice, and school change." Harvard Educational Review 60 (4): 443-467.

Gobo, G. 2008. Doing Ethnography. Thousand Oaks, CA: Sage. 
Greenwood, D., and M. Levin. 2003. "Reconstructing the relationships between universities and society through action research." In The Landscape of Qualitative Research: Theories and issues, edited by N. K. Denzin, and Y. S. Lincoln (2nd ed.): 131-166. Thousand Oaks, CA: Sage.

Hastrup, K. 1995. A Passage to Anthropology: Between experience and theory. New York: Routledge.

Hastrup, K. 2001. "Writing ethnography. State of the art." In Anthropology and Autobiography, edited by H. Callaway, and J. Okely: 116-133. London: Routledge.

Holt, N. 2003. "Representation, legitimation, and autoethnography: An autoethnographic writing story." International Journal of Qualitative Methods 2 (1): $18-28$.

Koro-Ljungberg, M. 2004. "Impossibilities of reconciliation: Validity in mixed theory projects." Qualitative Inquiry 10 (4): 601-621.

Lather, P. 2007. Getting Lost: Feminist efforts toward a double(d) science. Albany, NY: State University of New York Press.

Lincoln, Y. S. 1995. "Emerging criteria for quality in qualitative and interpretive research." Qualitative Inquiry 1(3): 275-289.

Marullo, S., and B. Edwards. 2000. "From charity to justice. The potential of universitycommunity collaboration for social change.” American Behavioral Scientist 43 (5): 895-912.

Masschelein, J. 2004. "How to conceive of critical educational theory today?" Journal of Philosophy of Education 38 (3): 351-367.

McLeod, J. 2000. Beginning Postcolonialism. Manchester: Manchester University Press. 
Okely, J. 2001. “Anthropology and autobiography: Participatory experience and embodied knowledge." In Anthropology and Autobiography, edited by $\mathrm{H}$. Callaway, and J. Okely: 1-28. London: Routledge.

Priyadharshini, E. 2003. "Coming unstuck: Thinking otherwise about 'studying up'." Anthropology and Education Quarterly 34 (4): 1-19.

Rappaport, R. 1995. "Disorders of our own.” In Diagnosing America: Anthropology and public engagement, edited by S. Forman: 235-294. Ann Arbor, MI: University of Michigan Press.

Reason, P., and H. Bradbury, eds. 2008. The Sage Handbook of Action Research: Participative inquiry and practice. London: Sage.

Reed-Danahay, D. 1997. Auto/Ethnography. New York: Berg.

Rousseau, J.-J. [1762]1979. Emile, or on education. New York: Basic Books.

Salzman, P. C. 2002. “On reflexivity.” American Anthropologist 104 (3): 805-813.

Skocpol, T. 2003. "Doubly Engaged Social Science: The Promise of Comparative Historical Analysis." In Comparative Historical Analysis in the Social Sciences, edited by J. Mahoney, and D. Rueschemeyer: 407-428). Cambridge and New York: Cambridge University Press.

Smeyers, P. 2006. “'What it makes sense to say': Education, philosophy and Peter Winch on social science.” Journal of Philosophy of Education 40 (4): 463-485.

Smeyers, P, and B. Levering. 2001. Grondslagen van de wetenschappelijke pedagogiek. Modern en Postmodern. Amsterdam, Netherlands: Boom.

Spry, T. 2001. "Performing autoethnography: An embodied methodological praxis." Qualitative Inquiry 7 (6): 706-732.

Tuhiwai Smith, L. 1999. Decolonizing Methodologies: Research and indigenous peoples. London: Zed Books. 
Vermeersch, P. 2006. The Romani Movement: Minority politics and ethnic mobilization in contemporary Central Europe. New York: Berghahn.

Wagner, J. 1997. "The unavoidable intervention of educational research: A framework for reconsidering researcher-practitioner cooperation." Educational Researcher 26 (7): 13-22. 